\title{
How flipped classroom teaching methods in first year studying succeed
}

\section{Anja Pfennig}

HTW Berlin, University of Applied Sciences, Berlin, Germany.

\begin{abstract}
Flipping the classroom is a method to let students study on their own and then take time to discuss their questions and do extended hands-on lectures or exercises in class - or in the case of the covid-19 pandemic during plenary online sessions. First year mechanical engineering students use different teaching materials (mainly lecture videos, lightboard videos and micromodule lectures) to study from a distance and comprehend the principle underlying science in theory. Then the online plenary lectures offer the opportunity to apply their knowledge and transfer different scientific aspects of the course to get the bigger picture. Exercises, worked solutions, selfassessed tests and peer-instruction during present time help students to check on their learning progress. However, the self-study periods and (online) plenary sessions need to be guided carefully. To meet the course learning outcome and overcome the diversity of a first year class various practical leads have to be fulfilled to turn flipped classroom teaching into success.
\end{abstract}

Keywords: Inverted classroom; flipped classroom; online teaching; lecture videos; first year students; material science. 


\section{Introduction}

Diversity of learning history, social aspects hindering full time studying, job commitment and deficient preparation from highschool are some of multiple aspects to challenge lecturer in higher education first year classes. Often lecturer face a number of students only interested in passing rather than learning about the important basics required to pass consecutive classes, the second semester or compulsive laboratory courses. Flipping the classroom: Berret (2012), Brame (2015), Fischer and Spannagel (2012), Braun et al. (2012), Seteren et al. (2019), Pfennig (2019, Pfennig (2020) seemed to be the appropriate medium to gain student's attention, motivate them right from the start to continuously study and acquire good exam results assuring each to easily pass the graded exam the second semester: Pfennig: (2016).

The flipped classroom constitutes a role change for instructors, who give up their front-ofthe-class position in favour of a more collaborative and cooperative contribution to the teaching process. ...The flipped model puts more of the responsibility for learning on the shoulders of students.... Activities can be student-led, and communication among students can become the determining dynamic of a session devoted to learning through hands-on work. What the flip does particularly well is to bring about a distinctive shift in prioritiesfrom merely covering material to working toward mastery of it: Educause (2016)

The principle of flipping the classroom requires students to study the science on their own without time limit and then take time to raise questions and discuss details, solve hands-on problems, perform group work and master difficult problems in class. Because the method clearly enables students to discuss early and communicate in equal measure: Pfennig (2016), Pfennig (2018) Material Science at HTW Berlin, Germany is taught based via "design-led" teaching approach: Ashby et al. (2013) including flipped classroom teaching scenarios.

Although Setren et al. (2019) report success for the flipped classroom teaching method only for MINT courses neglecting progress for economic related teaching Gulley et al. (2016) state that the understanding and retention of course material was improved along with effective use of time in class. Generally, students are given more responsibility for their learning progress during the semester which was found to encourage critical thinking: CSU (2015), Lord (2012) and results in deeper learning outcomes: Goto and Schneider (2010), Simon et al. (2010). Additionally, inverting the classroom has a positive effect on selfefficacy beliefs and intrinsic motivation: Thai et al. (2017).

With the covid-19 pandemic and the need to transfer face-to-face time into online-sessions, however, the self-study periods and (online) plenary sessions need to be adapted carefully. This paper shares the most important (and sometimes astonishing) insights of 7 years inverted classroom teaching along with praxis examples from an introductory material science course. 


\section{Practical leads for inverted classroom teaching}

The Material Science course introduced earlier: Pfennig (2018), Pfennig (2019), Pfennig (2020) offers cumulative assessment of micro-modules and therefore a manageable work load for approximately 45-70 students per semesster - especially in a fully online teaching environment, such as summer and winter semester 2020/2021 (37/68 students). Students may individually chose, combine and study from alone or in study groups from a distance. Exercises, worked solutions, self-assessed tests and peer-instruction during present time help students to check on their learning progress. To meet the course learning outcome and overcome the diversity of a first year class many practical leads have to be fulfilled to turn flipped classroom teaching into success. The author refers to success in accordance to formative assessment: Pfennig (2018/1) including formative assessment such as detailed questionnaires, tests, quizzes etc. as well as to evaluations throughout and at the end of the semesters as well as discussions with collegues teaching teaching advances courses such as design or manufacturing engineering. Out of 20 the author will introduce her 7 main practical leads for succeeding in a blended learning and fully online learning environment:

\subsection{Start with low threshold tasks when assessing the first flipped classroom lecture}

To secure students that they have studied well and motivate everyone right from the beginning we have made very good experience with low threshold first problems. These can be of scientific depth, but also be used to get acquainted with the organization of the CMS (content management system), where to find content, how to upload files, how to find group members and where to find the personal course credits.

Example Material Science: In material science it is very important to know microstructures because they explain e.g. mechanical and thermal properties of engineering materials. Students worked on short lectures showing many different pictures of microstructures and had to put them in order as an "end-of-the-lecture" quiz. Everyone scored fully! Online sessions were used to match components with known microstructures and properties and ranked according to memory cards in break-out sessions.

\subsection{Close guidance of self-study period is highly advised}

Self-study periods have to be guided to achieve a positive learning outcome. That is: lectures need to be assigned precisely, Tasks and quizzes explained, lecture videos have to have an overall research/learning question and guided by self-assessing questions (figure 1, which may then be used to assess the course formally in a second step). Assigning pages in pdfs, lectures or papers to prepare for the next (online) meeting runs the very likable risk of students remaining unprepared or with insufficient background knowledge. Also, students are insecure of what to prepare and if they study "the right" content - especially first semester students. 

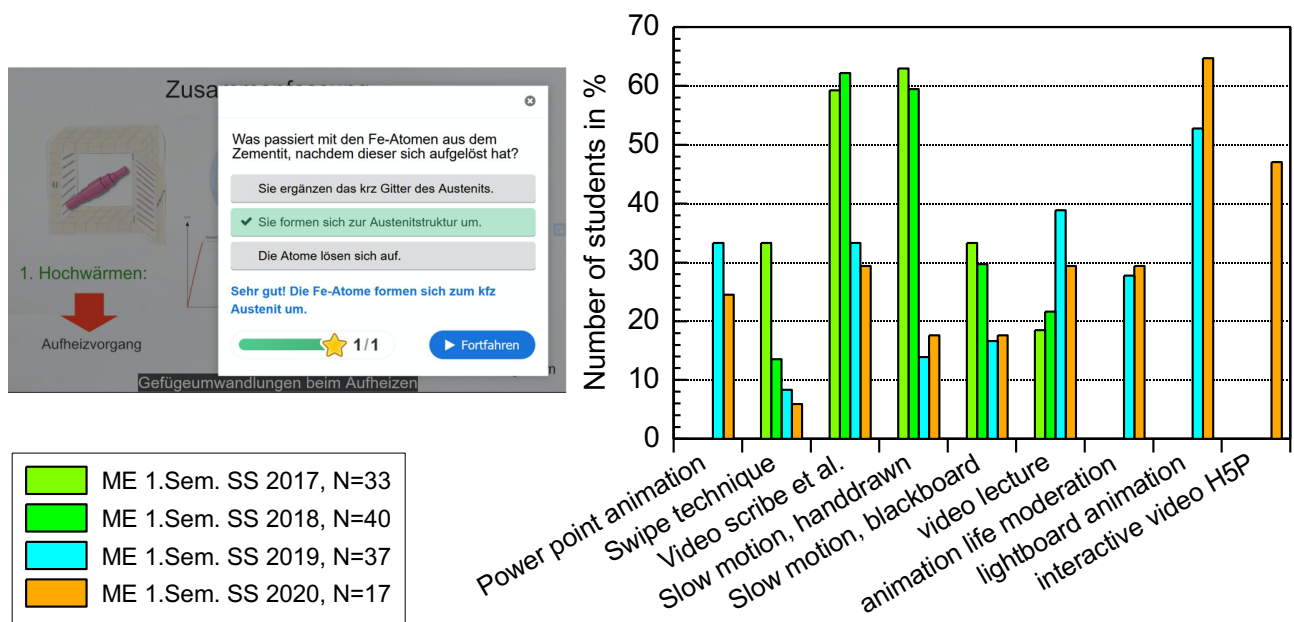

Evaluation of lecture film formate

Figure 1. Evaluation of lecture video format and example of a H5P interactive lecture video with subtitles.

Example Material Science: We provide around 80 peer-to-peer reviewed lecture videos: Pfennig (2018), Pfennig (2019) (https://www.youtube.com/user/cutsandtalks). However, these are converted into H5P interactive lecture videos (https://h5p.org/) with various multiple choice content questions throughout the video. Also subtitles are added to give students both opportunities: reading and listening while watching. The learning output is much higher and "joy of use" greater according to students" feedback (figure 1).

\subsection{The learning outcome was more successful in homogeneous study groups (break-out sessions)}

Although heterogeneous groups are stated many times before to be more successful than homogeneous study groups this did not account for the face-to-face (online) sessions when flipping the classroom. For every student to meet the minimum course requirement there was no use if they were part of a group with one or two students solving all problems without the chance of understanding or trying out for the solution themselves. It was necessary for students to understand that the flipped classroom teaching model does not require mastering the scientific content but having the idea what the meaning of the self-study content is and to integrate their (half) knowledge in hand-on problem solving. Errors most likely lead to deeper understanding. Note, that these finding are clearly of subjective teaching experience of the author and might not agree with other lecturers in higher education or other findings/studies. This is a well-acknoledges statement to be critically discussed in future.

Example Material Science: Here: phase diagrams: Pfennig (2018/2). During regular and online semester students are asked to group themselves according to depth of understanding. 
The lecturer explains in detail why this grouping is important to admit insecurity or shaming, mobbing or even resigning from the (online) session. Generally, this has not been a problem since 2015 ! In contrast, students were rather thankful to either be challenged or get the chance of working in their own study tempo, be guided and have the chance of asking questions without the full audience. This flipped classroom teaching session succeeded in present: Pfennig (2018/2) and also online (break-out sessions) in 2020/2021.

\subsection{Learning outcome, assessment and workload should be clear from the beginning and transparent throughout the entire semester}

Fairness and transparency are one of the most important issues to enhance self-instructed learning as indispensable principle of the flipped classroom method. Students need to know about their study progress and grading. Fading study motivation is the most acknowledged reason for early drop out of first year students. If everyone knows exactly what he/she is aiming at (in terms of passing and assessment) study motivation is high for every student to reach the personal course objective.

Example Material Science: Weekly assignments provide a timeline with deadlines, percentage of grading for each activity (figure 2), requirements for the week and certain tasks along with classification in the holistic course setting in a Moodle course. Alerts and messages remind students of not yet compiled work. Since 2016 no first year student failed material science (note, the overall grading did not significantly improve over the traditional course assessment via final exam: Pfennig (2020) and Pfennig (2018).

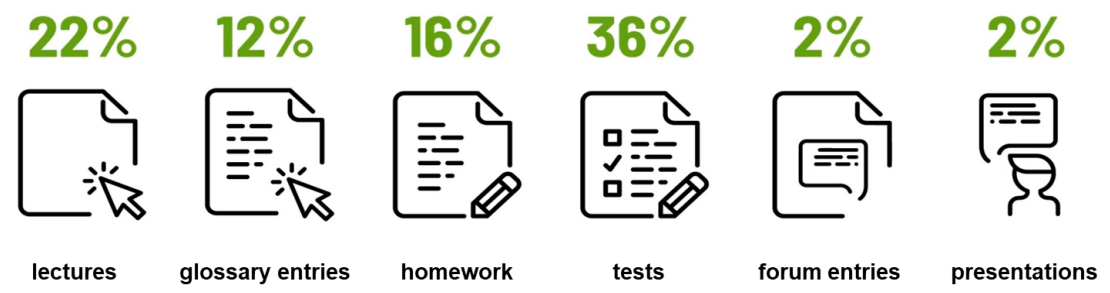

Figure 2. Transparent grading of the cumulative course assessment.

\subsection{Organize the CMS (content management system) formally not according to content.} Alternatively use the weekly solution

Student feedback clearly demanded to organize the learning contents in the Moodle course according to the format of the learning material rather than learning history or content. It seems to be much easier for students to navigate a complex CMS if the activities are in order of format (even if the lecturer wanted to provide a smooth learning guidance along the various activities. Alternatively, the weekly course format may be chosen from the CMS offering the same close guidance as the format structuring does. 
Example Material Science: Top of the Moodle course are assessed activities, weekly assignments, compilation of lecture films and compilation of lightboard lectures. Every theme is set up following the same protocol: interactive links (to various additional teaching material, such as mind maps, scripts, PPT, etc.), micro-lectures, problems with worked solutions, lecture videos, interactive videos and tests (figure 3).
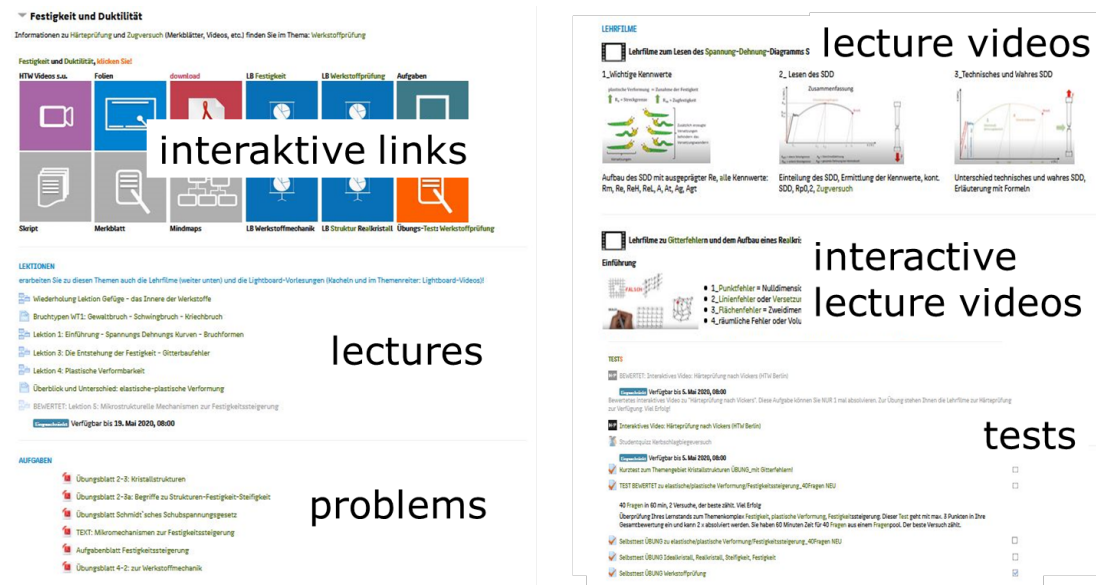

Figure 3. Organization of the Moodle course according to format-not content.

\subsection{Use templates to summarize the learning outcome of each study session}

When students work in micro groups appreciation and evaluation of their efforts and results need to be given directly in order to conclude a flipped classroom session successfully. Also, results from different groups may be compiled easily and provided easily for the entire class - after careful revision by both - lecturer and plenum.

Example Material Science: Usually, during face-to-face (online) time students work on solutions or presentation of (study) results following a strict template combining: the problem, the solution (written or graphical), transfer to mechanical engineering and difficulties. These "filled- in templates" are then distributed digitally for the entire course after presentation and content/graphic revision.

\subsection{Do not use online-sessions for content transfer. Solving problems, discussions and hands-on projects are much more effective}

When lecturers repeat the scientific content from the self-study period weak students or students who did not study at all do not feel the need to study by themselves. Hence, they are constantly unprepared and fall behind the course objective fast. On the other hand willing and high performing students feel betrayed because their work and effort is not acknowledged. Solutions may be classroom response where the lecturer has the possibility 
to explain details according to the answers, especially the distractors. Offering the students time for Q\&A is another approach to give knowledge input without lecturing. It is recommended to use the (online) face-to-face time for transfer and worked problems.

Example Material Science: In general, each plenary session (online or face to face) starts with classroom response (invote, flinga, mentimeter, kahoot, etc.) accompanied by students asking questions that are answered by the plenum and lecturer. Then students deal with theoretical or hands-on problems presented and discussed in class (these could even be handmade models made from aluminum foil and toothpicks! practicing and visualizing 3-D imagination of lattice structures). Therefore, one students (voluntarily) takes notes for everybody and two students facilitate the discussion, with the lecturer staying behind. Templates of the different results (written or pictures) wrap up the particular session.

\section{Conclusion}

Flipping the classroom challenges lecturers but it also offers a profound solution to achieve a more homogenous learning outcome. Students may individually choose, combine and study from alone or in study groups from a distance. To meet the course learning outcome and overcome the diversity of a first year class the author shares her 7 main practical leads to succeed (online) in the flipped classroom teaching method:

1. Start with low threshold tasks when assessing the first flipped classroom lecture.

2. Close guidance of students` self-study period is highly advised.

3. The learning outcome is more successful in homogeneous study groups.

4. Transparency of learning outcome, assessment and workload right to begin.

5. Organize the online course formally (not content). Alternative: arrange by the week.

6. Use templates to summarize the learning outcome of each study session.

7. Use (online) face-time for interacting hands-on problems not content transfer only.

These practical leads are based on individual teaching experience of the author and might not be in agreement with other studies or lecturer experiences (especially study groups is a sensitive topic). All of these leads will be of close survey in future classes and critically discussed throught future semesters.

\section{References}

Ashby, M., Shercliff, H., Cebon, D. (2013). Materials Engineering, Science, Processing and Design, 2013: ISBN-13: 978-0080994345, Pub date: Oct 02, 2013 ( $3^{\text {rd }}$ edition).

Berrett, D. (2012). How 'flipping' the classroom can improve the traditional lecture, The Cronicle of Higher Education.

Brame, C.J. (2015). Flipping the Classroom, http://cft.vanderbilt.edu/files/Flipping-the- 
classroom.pdf, call: 09/2015.

Carberry, A.R., Siniawski, M.T., Dionisio J.D.N. (2012). Standards-based grading: Preliminary studies to quantify changes in affective and cognitive student behaviors. IEEE Frontiers in education conference, Seattle, WA.

Colorado State University (2015). Using Peer Teaching in the Classroom. http://teaching.colostate.edu/tips/tip.cfm?tipid=180.

Educause (2016). Educause Learning initiative (2016). Things You Should Know About Flipped Classrooms, https://net.educause.edu/ir/library/pdf/eli7081.pdf, call: 01/2016.

Fischer, M und Spannagel, C (2012). Lernen mit Vorlesungsvideos in der umgedrehten Mathematikvorlesung, in Desel, J., Haake, J.M. und Spannagel, C. (Hrsg.), DELFI 2012, Die 10. E-Learning Fachtagung Informatik der Ges. f. Inf. e.V., S. 225-236, Bonn: Köllen Druck + Verlag, Copyright C Gesellschaft für Informatik.

Goto, K. \& Schneider, J. (2010). Learning through teaching: Challenges and opportunities in facilitating student learning in food science and nutrition by using the interteaching approach. J. of Food Sci. Education, 9(1), 31-35.

Lord, T. (2012). 101 reasons for using cooperative learning in biology teaching. The American Biology Teacher, 63/1, 30-38.

Pfennig, A. (2016). Inverting the Classroom in an Introductory Material Science Course, Procedia - Social and Behavioral Sciences, 228, 32-38.

Pfennig, A. (2018). Improvement of learning outcome in material science through inverted classroom techniques and alternative course assessment. JFLET Journal of Foreign Language Education and Techn., 3(1), 148-162.

Pfennig, A. (2018). Flipping the classroom and turning the grades - a solution to teach phase diagrams to engineering students. JFLET J. of Foreign Lang. Educ. Techn., 3(1), 18-34.

Pfennig, A. (2019). "Making it Work" - Practice Examples of Preparation and Embedding Peer-to-Peer Lecture Films in Successful Inverted Classroom Scenarios. PEOPLE: International Journal of Social Sciences, 5/1, 640-655.

Pfennig, A. (2020) Improving learning outcome for GSL (German as a Second Language) students in a blended learning cumulative assessment material science course. Int. Conf. on Education and E-Learning ICEEL 2020, 06-08.Nov., Tsuru, Japan (online).

Setren, E., Greenberg, K., Moore, O., Yankovich, (2019). Effects of the Flipped Classroom: Evidence from a Randomized Trial. SEII Discussion Paper \#2019.07, MIT Department of Economics, National Bureau of Economic Researc.

Simon, B., Kohanfars, M., Lee, J., Tamayo, K, \& Cutts, Q. (2010). Experience report: peer instruction in introductory computing. Proceedings of the 41st ACM Technical Symposium on Computer Science Education, 341-345.

Thai, N.T.T., De Wever, B., Valcke, M. (2017). The impact of a flipped classroom design on learning performance in higher education: Looking for the best "blend" of lectures and guiding questions with feedback, Computers \& Education, 107, 113-126. 